\title{
Câmera e vídeo na escola: quem conta o que sobre quem?
}

Adriana Maricato de Souza

Jornalista e Mestre pela ECA/USP.

E-mail: adriana_maricato@yahoo.com.br

\section{A partir da narrativa audiovisual, o jovem compreende melhor seu universo cultural}

A maneira como o vídeo, a televisão e demais equipamentos eletrônicos têm sido pensados em relação à escola no Brasil cai numa armadilha chamada pelos argentinos Jorge Alberto Huergo e María Belén Fernández ${ }^{1}$ de escolarização da mídia. Existe um abismo entre a cultura escolar, fundamentada no código escrito em suas modalidades denotativas - portanto, de desenvolvimento científico e linear de conteúdos -, e a cultura midiática, na qual predomina a narrativa de ficção. A escola privilegia o código escrito por tradição, e não sabe atuar com o código audiovisual tão presente na cultura atual.

Embora não exista antagonismo entre as duas linguagens - textos escritos apresentam amplas possibilidades expressivas e interpretativas -, há a noção de superioridade da escrita e inferioridade do audiovisual entre os professores. Puro preconceito e desconhecimento, favorecendo o paradoxo da escolarização da mídia, quando esta é indomesticável. Pela ação de pedagogos e professores, a instituição escolar tende a aceitar propostas de trabalho em comunicação compreensíveis na sua cultura profissional. Se o projeto se subordina aos padrões conhecidos por pedagógicos - palestras e aulas expositivas, dinâmicas baseadas na organização linear de conteúdos e análise -, é visto com simpatia. Mas, se a proposta for de produção de narrativas e não tem vínculos com os tradicionais critérios pedagógicos, conteúdos apropriados e controle sobre a narrativa, a resistência surge em vários níveis.

$O$ vídeo não substitui a escrita; trata-se de outra linguagem cuja produção depende de habilidades desenvolvidas pela leitura-escrita. Então por que fazer vídeo na escola? A linguagem audiovisual predomina na nossa cultura através da televisão e outros meios eletrônicos. Ela cria uma realidade paralela: o que

1. HUERGO, Jorge Alberto; FERNÁNDEZ, María Belén. Cultura escolar, cultura mediática. Intersecciones (Intersecções). Santa fé de Bogotá: Universidad Pedagógica Nacional, 2000. 
existe passa na televisão; o que não passa, não existe. A televisão é o espelho social e propõe imagens do que seria a sociedade. É desnecessário dizer que a escola pública é invisível na TV, e quem está longe desta realidade constrói idéias estereotipadas sobre educação. As tradicionais representações da escola pública, na telinha, seguem os padrões de representação dos grupos sociais excluídos da mídia, com conotações negativas ou ridículas como criminalidade, pobreza, professores e alunos dos programas de (mau) humor, de mau gosto. As escolas das novelas são privadas, freqüentadas por brancos e ricos, professores com padrão de consumo inacreditável.

A escola pública precisa produzir suas próprias narrativas audiovisuais e torná-las visíveis para a comunidade. Mas não serve qualquer narrativa, produzida de qualquer jeito, subordinada aos tradicionais critérios pedagógicos de controle e censura das pessoas dentro das escolas.

Num espaço onde primeiro o diretor e depois os professores são donos das vozes, a narrativa audiovisual tem o potencial de gerar diálogo dentro da escola e com a comunidade do entorno.

A vantagem do vídeo é que, neste caso, a linguagem não se subordina aos usos escolares - embora a lectoescrita (leitura e escritura) possa ser agente do diálogo, o uso escolar a reduz basicamente aos textos didáticos e sistemas de provas.

Desprezada pela instituição escolar, a linguagem audiovisual entra em choque com a cultura escolar, impregnada no cotidiano das relações entre as pessoas e entre escolas e órgãos hierarquicamente superiores. O processo pedagógico que ignora a existência do repertório cultural dominante - audiovisual - não faz sentido para os alunos, especialmente os das classes mais baixas, que são justamente os atendidos pelas escolas públicas. Sua maneira de interpretar o mundo é radicalmente diferente do que pressupõem professores e especialistas, não só por causa da televisão, mas também por suas origens socioculturais, em que predominam o oral e o audiovisual.

\section{O PRECONCEITO CONTRA A TELEVISÃO}

Muitos teóricos definem a televisão como o meio da publicidade e, portanto, do estímulo ao consumo. Os programas de televisão sempre vendem alguma coisa - idéias, valores, produtos e a própria programação. A publicidade está presente em todos os seus gêneros, do começo até o fim: "Tudo na televisão incita ao consumo, porque a televisão é reflexo e sustentação de uma sociedade que vive para o consumo"2. Basta observar como o Jornal Nacional promove a programação da Rede Globo, misturando narrativas sobre fatos (ainda que duvidemos das versões globais) com publicidade sobre estréias da emissora, programas específicos, novelas ou indução do público a votar no próximo eliminado do reality show. Uma análise mais atenta do telejornalismo mostra como essas produções são, na realidade, propagandas (de corporações, de Estado, de organizações) disfarçadas. Mesmo

2. FERRÉS, Joan. Televisão e Educação. Porto Alegre: Artes Médicas, 1996. temas menos comuns na mídia, como projetos sociais, geralmente são plantados por estratégias de assessoria de imprensa. O público acaba percebendo a propaganda/ficção como realidade, pois a imagem cria a ilusão de retrato. 
Mas estamos falando de emissoras comerciais e do uso da linguagem audiovisual a serviço do lucro e da audiência, ditando padrões de linguagem também para as emissoras públicas e educativas. A linguagem audiovisual propriamente dita, assim como a linguagem escrita ou qualquer outra, não se subordina a modelos estáticos de expressão e interpretação. Há, sem dúvida, a predominância da televisão comercial e da programação para entretenimento na linguagem audiovisual mais conhecida, formando também o gosto do público. Daí o preconceito contra o audiovisual, não só da instituição escolar como também de pesquisadores do assunto, analistas e não-criadores. Na verdade, não há uma única forma de produzir narrativas audiovisuais nem um único gosto possível, mas sim a predominância do modelo de incitação ao consumo.

A cultura midiática, ditada pelas corporações, forma o gosto do público e coloniza nossos interiores, pedindo respostas passivas através do consumo de bens e idéias. A mídia propõe imagens da educação, mostrando escolas e comunidade escolar sem relação com as escolas públicas existentes. Sendo a TV um espelho social que não reflete, cria um vazio na percepção da comunidade escolar e alimenta a dinâmica da propaganda do desejo do ideal. A escola desejada e inatingível só existe na ficção - é bonita, grande, tem áreas verdes, todos são brancos e ricos (preferencialmente loiros de olhos azuis), professores bem preparados, bem pagos, descansados e compreensivos, alunos disciplinados, e o aprendizado acontece com sucesso. Não há conflitos sociais sérios, apenas problemas pessoais sem impacto sobre a instituição.

Alunos, professores, funcionários e comunidades em torno das escolas públicas não se reconhecem na tela, nem no seu cotidiano invisível. Reconhecem-se apenas nos índices de criminalidade na periferia e nos fracassos da educação pública exibidos pela televisão. A imagem criada para si próprios, através do espelho da mídia, paralisa a criatividade. É consenso que a escola pública precisa mudar para atender a sua nova clientela, imersa numa realidade social dramática e herdeira de tradições culturais desprezadas pela instituição. A cultura midiática é um dos elementos fundamentais a serem incorporados nessa mudança.

Existe uma maneira de quebrar o círculo vicioso desse processo de identificação negativa da escola pública: elaborando narrativas audiovisuais. Através da produção de vídeos, desmistifica-se a linguagem, o meio televisivo e a autoria social do discurso. E evidencia-se o contraste entre representações da escola e da educação na TV e a comunidade escolar real. Na sociedade contemporânea, olhar-se na tela é fundamental para se reconhecer como cidadão. Quem conhece um processo criativo e crítico de produção de vídeo nunca mais assiste à TV inocentemente.

\section{PRODUÇÃO AUDIOVISUAL NA ESCOLA}

Os meios de comunicação e as novas tecnologias produzem alfabetizações múltiplas, ou alfabetizações pós-modernas, estruturando a percepção das pessoas no sentido de que existe uma incapacidade para adotar um único e fixo ponto de vista da realidade ${ }^{3}$. Citando Peter McLaren, Huergo e Fernández, acontece uma colonização do interior das pessoas mais intensa do que no caso da escola, cujo funcionamento estabeleceu padrões na vida social. Evidentemente, a

3. HUERGO, Jorge Alberto; FERNÁNDEZ, María Belén. Cultura escolar ..., op. cit. 
heterogeneidade dentro da escola aponta para configurações diferentes. Todos estão expostos aos meios eletrônicos, mas adultos, adolescentes e crianças se relacionam de maneira diferente com esta cultura.

Para o argentino Aníbal Ford ${ }^{4}$, as culturas eletrônicas colocam questões específicas das culturas orais: primazia do concreto sobre o abstrato, do nãoverbal, do quinésico (imagem em movimento) e proxêmico (realidade próxima), facial e espacial. As estratégias cognitivas das culturas urbanas da sociedade dos meios de comunicação de massa têm mais a ver com estruturas orais, emotivas e intuitivas do hemisfério direito do cérebro do que do esquerdo. Assim, as novas formas de conhecimento não são recortadas, lineares, organizadas e controladas pela escola, que se pauta pela lógica escritural - embora nem mesmo o código escrito seja desenvolvido com competência, como destaca Edmir Perrotti ${ }^{5}$. Talvez a ausência de diálogo na escola desestimule o desenvolvimento de habilidades lingüísticas.

As análises sobre a relação entre cultura midiática e escola são, em geral, desenvolvidas tendo como referência a recepção dos espectadores e usuários dos meios eletrônicos, nos quais predomina a emoção. Os autores destas reflexões têm uma relação predominantemente passiva (no sentido de que são receptores de produtos audiovisuais e tecnológicos) com os meios eletrônicos. Por isso deixam passar despercebido um aspecto fundamental: a produção das narrativas - vídeos, programas de computador, elaboração de páginas na internet - é, para os profissionais envolvidos na sua realização, atividade abstrata e complexa desenvolvida por especialistas.

4. Citado por HUERGO, Jorge Alberto; FERNÁNDEZ, María Belén. Cultura escolar..., op. cit.

5. Entrevista cedida à autora em maio de 2003. Edmir Perrotti é professor doutor do Departamento de Biblioteconomia e Documentação da Escola de Comunicação e Artes da USP.

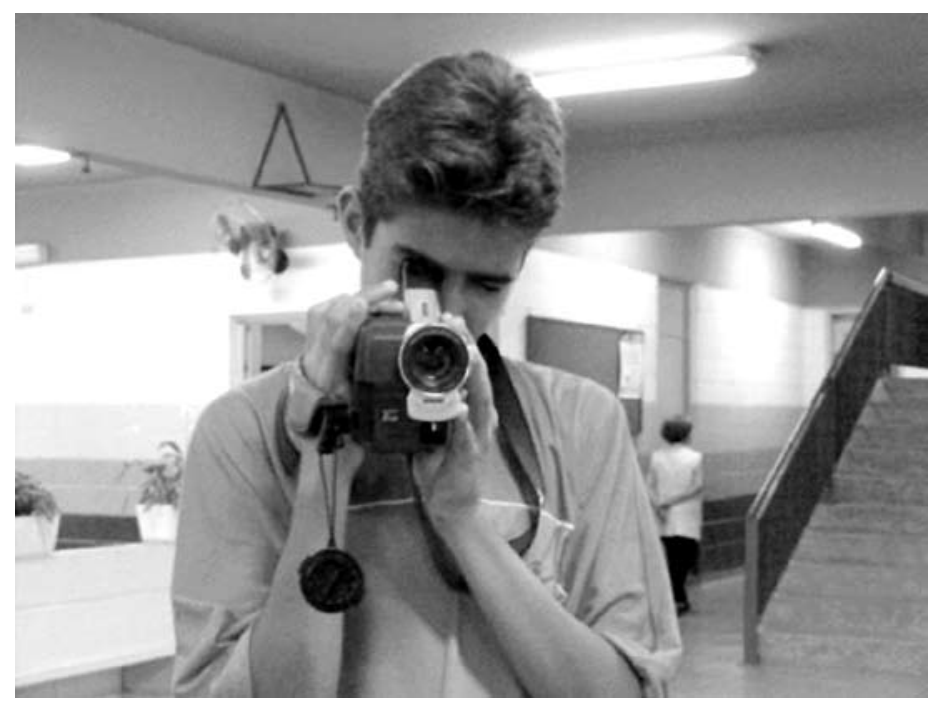

Aluno do ensino fundamental aprende os segredos de funcionamento da câmera de vídeo da EMEFM Darcy Ribeiro.

No caso do vídeo, a produção de narrativas, segundo critérios técnicos e estéticos de qualidade, envolve as mesmas operações cognitivas que compreende a elaboração de textos escritos: imaginação, planejamento, análise, classi- 
ficação, ordenação, seqüenciação, relação entre elementos, elaboração verbal. Uma equipe de produção pode ser grande: composta de quem escreve, quem produz, quem dirige, quem opera a câmera, quem cuida da cenografia, quem atua, quem cuida do som, quem edita, entre muitas outras funções possíveis. A dimensão da equipe depende do orçamento disponível. A produção de narrativas audiovisuais, como se vê, é uma elaboração complexa e cara por natureza da atividade - envolve equipamentos e material de consumo caros, além de precisar de trabalhadores especializados.

Na produção de linguagem, a divisão entre teoria e prática é mera abstração acadêmica, perpetuada na formação universitária, e comporta elementos técnicos e simbólicos inter-relacionados. Para além da análise da linguagem audiovisual, a criação de narrativas em contraposição à mídia eletrônica corporativa só pode ser realizada por quem sabe produzi-la. Por um motivo muito simples: a recepção do audiovisual é predominantemente emocional, e uma análise da linguagem ignorante do processo de produção de significados se refere à análise propriamente dita da cultura escolar, mas não à cultura midiática, que não segmenta aspectos racionais ou emocionais.

Educar com o vídeo não se limita a operar os equipamentos, mas dar voz e cara aos excluídos com qualidade de linguagem e criatividade. Quem educa com vídeo tem que saber escrever bem com uma câmera para conduzir um processo pedagógico efetivo. Educar com uma câmera implica garantir que os conflitos e contradições das instituições escolares sejam expressos (na mídia convencional o discurso é homogêneo, assim como no espaço escolar os mais fracos e subordinados se calam), reconhecendo diferenças e alimentando o diálogo.

Só quem domina conceitos específicos pode desenvolver um processo consistente de formação de professores e alunos para o uso do vídeo. Nada diferente do que acontece com a leitura-escrita: quem domina conceitos e códigos específicos conduz um processo de aprendizagem efetivo. Do contrário, o vídeo será rejeitado pelos seus autores, se não tiver qualidade técnica e de linguagem, sendo meio de expressão institucional, e não dos alunos e professores.

O mau enquadramento da imagem pela câmera pode enterrar a autoestima do aluno ou do professor que participa da atividade. E a abordagem de qualquer tema pode reproduzir padrões dominantes da mídia tradicional e valores de educação falidos, ecoando nos monólogos das paródias da TV ou nos depoimentos intermináveis. $\mathrm{O}$ olhar de quem assiste a produtos tecnicamente refinados não aceita vídeos malfeitos.

O sonho do educador audiovisual é promover a exibição pública do vídeo produzido numa oficina para que pais, alunos e membros da comunidade possam assistir a ele. Tais vídeos promovem a identificação do público com o grupo, autor da narrativa, e os discursos são legitimados socialmente quando aparecem numa tela de TV. A tela pode projetar a diversidade de narrativas da escola e promover o diálogo. Esta é a parte mais difícil do complicado processo de quebrar resistências em todos os níveis, porque a cultura midiática não é uma prioridade na escola. 


\section{A CULTURA TRANCADA NO ARMÁRIO}

Cultura midiática e tecnológica são elementos indissociáveis. Os equipamentos eletrônicos não produzem cultura sozinhos e a cultura audiovisual não pode ser produzida sem equipamentos. As escolas municipais de São Paulo têm câmeras de vídeo Hi8, videocassetes, DVDs e TVs de tela plana, mas quase não são usados. Quando o são, apenas reforçam práticas simplistas e autoritárias de comunicação. A maioria dos diretores desencoraja explícita ou implicitamente o uso dos seus equipamentos por parte dos professores e alunos.

Câmeras de vídeo permanecem trancadas e eventualmente são usadas para registros, e às vezes existem duas câmeras numa escola. Por inércia, equipamentos tendem a ser apenas alguma coisa que deve ser trancada porque pode quebrar, ou para fazer deles o uso que os adultos consideram adequado. Em 2002, as conexões de internet estavam, em muitos casos, instaladas nas secretarias das escolas! A entrega de equipamentos não implica sequer instalação adequada, tudo depende de quem se encontra na escola no momento (para quem a tecnologia é um mistério) e há muita burocracia para a criação de soluções autônomas e ágeis. Os adultos não sabem o que fazer com a tecnologia nem criam condições para que os alunos tenham acesso de fato aos recursos mais simples que ela oferece.

A linguagem audiovisual, cheia de possibilidades expressivas, acaba sendo reduzida à pobreza de idéias que marca a maioria das propostas pedagógicas. Usar uma câmera para fazer trabalhos escolares soa demasiado simplista: subordina a linguagem ao conteúdo e pode produzir vídeos intragáveis. Discursos novidadeiros justificam práticas autoritárias, permanecendo tudo como está - hierarquia, lousa, produções artísticas sofríveis, livros novos intocados, censura aos temas

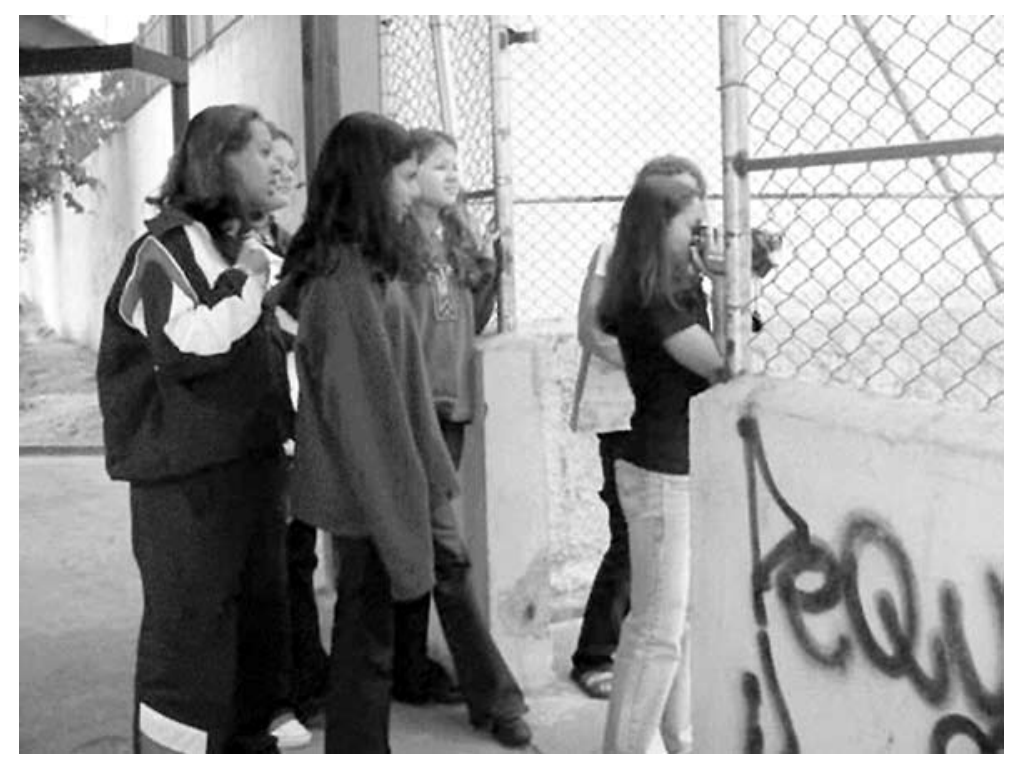

Representantes de grêmios brincam livremente com a câmera na quadra de esportes da EMEF João Augusto Breves. 
impróprios para menores -, porque o "buraco é muito mais embaixo". A escola não tem espaço para a expressão dos assuntos não programados, para as dimensões subjetivas da realidade escolar. Para Perrotti, "o projeto não é para

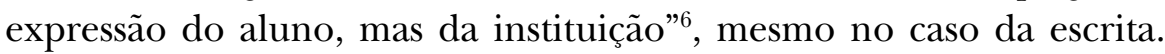

As narrativas sobre escola pública, predominantemente verbais, são elaboradas por professores, especialistas e pesquisadores. Os estudantes são privados de fazer seus próprios discursos por mecanismos tão violentos quanto é violenta a sociedade brasileira. O mais fraco, o mais pobre, o menos escolarizado se cala porque é assim desde sempre. No entanto, a cultura das crianças e adolescentes das periferias literalmente vem arrombando as portas e janelas das escolas públicas, cada vez mais parecidas com prisões, para trazer a realidade para a escola.

Em geral, os educadores morrem de medo da tecnologia. De fato, ela subverte a lógica da escola atual e cria muita insegurança sobre o papel dos professores e da própria escola no processo pedagógico. Trata-se de medo por desconhecimento do equipamento e da linguagem, que de certa forma marca um abismo entre gerações. Os alunos sabem intuitivamente e os professores não sabem, desmontando a hierarquia escolar quando estes deixam de ser os detentores do conhecimento.

A tecnologia entra fisicamente na instituição, mas não é incorporada aos processos pedagógicos. Além do abismo entre gerações, a resistência à cultura midiática ecoa o antigo medo dos professores de serem substituídos por computadores.

Equipamentos jamais poderão substituir gente. Na cultura permeada pela eletrônica, os educadores continuam sendo os mediadores entre o conhecimento e os alunos. Eles são necessários mesmo para o sucesso de projetos de educação a distância.

\section{OS ALUNOS NARRAM COM A CÂMERA}

Oficinas de vídeo de curta duração realizadas com alunos dos grêmios e com professores do Núcleo de Ação Educacional 10 (São Miguel Paulista e região), em setembro de 2002, revelaram muito do choque existente entre cultura midiática e cultura escolar. Embora a metodologia aplicada fosse a mesma, as duas experiências apresentaram grandes diferenças em decorrência das particularidades de cada grupo.

Em geral, crianças e adolescentes aprendem a narrar com a câmera com muita rapidez e facilidade. Eles têm um repertório passivo de linguagem audiovisual inexplorado, pois este conhecimento não é sequer reconhecido pela instituição. Não temem a tecnologia e aprendem rapidamente a lógica de programação da câmera, cabos de conexão com TV e vídeo. Em geral têm dificuldade de elaborar e expor idéias, por problemas relacionados ao aprendizado da leitura-escrita ou porque as poucas horas de trabalho não permitem uma atenção maior no desenvolvimento destas atividades.

Levando em conta os documentos e notícias sobre educação pública, há exceções impressionantes quanto ao desempenho dos alunos durante as ativi-

6. Entrevista com Ed mir Perrotti, em maio de 2003 
dades. Alguns apresentaram habilidades surpreendentes ao operar uma câmera pela primeira vez na vida. Outros se apropriaram rapidamente de técnicas de entrevista - atividades cognitivas ligadas ao raciocínio e à escrita - e obtiveram bons resultados em condições muito limitadas.

Os adolescentes das escolas públicas da zona leste vivem, no geral, numa situação social subordinada e aprendem desde cedo a manter a boca fechada. A escola é um espaço onde eles ouvem o que dizem os adultos. É difícil estimulá-los para que manifestem opiniões e idéias sem medo de errar. Numa das oficinas, a presença de adultos constrangeu os já calados participantes, que queriam contar uma história sobre drogas, assunto ilegal e impróprio para menores, embora presente em suas vidas. Já numa outra escola, a professora presente nunca interferiu nas atividades ou censurou os adolescentes, e sua postura respeitosa lhe rendeu o convite para votar no tema a ser desenvolvido.

As escolas públicas da periferia só aparecem na TV em reportagens policiais. Os adolescentes rejeitam o estereótipo da pobreza e falam sobre temas importantes nas suas experiências de vida: sexualidade (paquera, namoro, gravidez na adolescência), amizade, drogas, violência na escola e também coisas positivas da vida.

Os adolescentes, ao produzir suas narrativas e ver suas próprias imagens, se reconhecem como sujeitos capazes de contar histórias com a qualidade máxima que os recursos limitados lhes permitem.

Suas narrativas se contrapõem ao discurso das TVs comerciais sobre escola e adolescentes, e é quando eles percebem a existência de autoria social nos discursos da mídia.

"Não tem jeito, eu sou preto", reagiu Allan Sierra da Silva, um garoto negro de 17 anos da oitava série da EMEF Pedro Teixeira, presumindo não ser possível tornar sua imagem mais nítida. Assistindo ao vídeo produzido pelo grupo pouco depois, surpreendeu-se com a própria imagem: "Nossa, como eu sou bonito! Eu não sabia que eu era assim!”. Allan é um cinegrafista nato: sem monitoração, foi capaz de produzir imagens de um jogo de futebol com estabilidade, velocidade de movimento e iluminação adequadas com o sol a pino, a pior hora do dia para gravações e filmagens.

Sem censura para criar, em geral os alunos se expressam muito melhor com a câmera do que os professores, coordenadores pedagógicos e diretores. Aceitam a própria imagem e dos colegas com relativa naturalidade. Sem a tutela do que se entende tradicionalmente por pedagógico - a cultura midiática quebra os padrões de classificação de conhecimento por faixas etárias e moralidade -, contam muito bem as suas próprias histórias. As narrativas elaboradas falam sobre temas importantes para eles, sobre os quais a escola silencia ou transmite conhecimentos, sem dialogar de fato.

\section{CÂMERA NA MÃO DOS PROFESSORES}

Nas oficinas para formação de professores, os bloqueios são outros: em geral os professores sabem tudo, participam da formação para acumular conhecimentos úteis, elaboram discursos verbais capazes de justificar pedagogicamente 
qualquer coisa. Díaz afirma que "o discurso pedagógico tem se colocado como um princípio de controle sobre a reprodução do discurso, como uma gramática para a geração/regulação de textos e práticas de reprodução" ${ }^{\text {. O discurso }}$ pedagógico predominante não se relaciona com a realidade da escola pública brasileira, porque foi elaborado em outro lugar, sobre outra escola, para outras pessoas. Não cria nem fomenta soluções para a educação pública. A escola permanece a mesma, com problemas cada vez mais graves.

Muitos educadores chegaram à oficina de vídeo com percepções distorcidas da linguagem audiovisual disseminadas nacionalmente pela TV Escola (Projeto do Governo Federal de Fernando Henrique Cardoso), que promove uma audiência passiva a discursos audiovisuais prontos, baseados no pressuposto do conhecimento estático, analítico e cumulativo.

Por oficina de vídeo, muitos entenderam uso do videocassete em sala de aula a serviço da escola como ela é. Uma fita de vídeo seria como um livro didático, cujo conteúdo organizado sobre determinada disciplina serve como ferramenta de ensino. Em outras palavras, os professores queriam saber o que podem fazer antes e depois de apertar o play.

Muitos se surpreenderam quando foi solicitado não fazerem anotações e que não ensinariam nada através do vídeo - a complexa habilidade de elaborar narrativas audiovisuais leva anos de formação. Carregando o fardo de ter que saber tudo, eles demoram um pouco para admitir sua ignorância a respeito de alguma coisa, e se permitir experimentar e errar com a câmera. Alguns deles tremiam de pavor quando seguravam a câmera, como se fosse uma bomba prestes a explodir. Para muitos, de fato, era uma bomba simbólica. Sem mistério, cabos e plugues se tornaram apenas uns fios que funcionam se conectados no buraco da mesma forma e cor.

Ao final das três horas de atividade da oficina de vídeo, os professores se descobriram capazes de contar as suas próprias histórias. Para os mais fechados, a atividade quebrou resistências e proporcionou as argumentações que eles queriam. Para os mais abertos, como uma professora de Artes Plásticas com alguma experiência no uso da câmera, a atividade indicou detalhes e possibilidades para enriquecer suas propostas com os alunos. Para a maioria, foram horas prazerosas de elaboração de conceitos através da criação estética, demonstrando que a escola pública pode ser diferente sim, e pode haver diálogo efetivo entre professor (no caso o educador audiovisual) e alunos (professores do ensino fundamental).

A qualidade técnica das narrativas foi, em geral, inferior à dos adolescentes, o que se explica pelo medo dos equipamentos e por um olhar condicionado pela linguagem verbal. Um pouco vítimas e algozes de si próprios, a maioria dos professores tenta conciliar verborragia libertária com uma realidade cruel. Muitos dos vídeos produzidos expressam impotência diante dos problemas diários, em que reuniões e palavrório não resolvem situações de violência, desinteresse dos alunos, alcoolismo na sala de aula, desestruturação familiar, desemprego, miséria. A realidade social invade o espaço escolar e faz parte da educação pública, e os professores precisam de ajuda para criar soluções.
7. DÍAZ, Mario. Foucault, docentes e discursos pedagógicos, In: SILVA, Tomaz Tadeu (Org.). Liberdades reguladas: a pedagogia construtivista e outras formas de governo do eu. Petrópolis: Vozes, 1999 
Como afirma Díaz, "as transformações pedagógicas não residem na transformação de formas ou conteúdos pedagógicos, mas sim na transformação da visibilidade ou invisibilidade do poder" ${ }^{8}$. A autoria dos discursos audiovisuais revela quem detém o poder, e as oficinas realizadas no NAE10 possibilitaram uma reflexão sobre isso através da produção de narrativas. As ficções dos professores deram vazão aos temas que estão fora do discurso educacional porque falam de sentimentos; já as reportagens, graças às suas tênues relações com racionalidade, reafirmaram a tendência de discursos articulados como simulacros dos processos pedagógicos reais - no discurso, tudo é bem-sucedido.

Vídeos produzidos na escola por alunos e professores, dentro de uma perspectiva pedagógica consistente, quando exibidos em público, tornam essa realidade visível para a própria comunidade escolar. As produções mostram a escola como ela é vivida no cotidiano, e não a saudosa escola de alunos saídos dos comerciais de margarina presentes no imaginário social. O monólogo equilibrado da propaganda nada tem a ver com vídeos produzidos para estimular diálogo, porque o diálogo comporta discordâncias e conflitos.

Trazer o repertório e a experiência de crianças e jovens para dentro da escola implica reconhecer a cultura midiática, e permitir que a escola faça parte dela, não o contrário. A comunidade escolar pode produzir essa cultura com a câmera e demais equipamentos eletrônicos. Mas é necessário sair do círculo vicioso do trabalho escolar de conteúdos apresentados sem qualidade técnica e estética, de discursos homogêneos com objetivos curriculares. A crise da educação é profunda e, ao contrário do que o sistema os leva a acreditar, os professores e pedagogos não são capazes de responder a todas as questões apresentadas - econômicas, sociais, pedagógicas, culturais.

A escola precisa abrir as portas para a diversidade através da incorporação do trabalho de pessoas com outras especialidades e experiências. Está mais do que na hora de mobilizar o conhecimento produzido por pesquisadores e ativistas das mais diversas áreas, cuja formação demandou investimentos de governos e fundações de pesquisa, a serviço do interesse público. No caso da produção de vídeo, ao trabalhar com professores e diretamente com os alunos, essas pessoas podem auxiliar a escola a criar estratégias para incorporar a cultura midiática ao processo pedagógico. O processo não é rápido, nem fácil, muito menos barato e, naturalmente, gera resistências dentro de instituições engessadas pela tradição.

Os três vídeos produzidos por adolescentes da EMEF Pedro Teixeira foram posteriormente editados e podem ser visto através dos links:

Links para Real One Player para modem:

$<$ http://real.emm.usp.br:8080/ramgen/eca/beaba_p1_modem.rm>.

<http://real.emm.usp.br:8080/ramgen/eca/beaba_p2_modem.rm>.

<http://real.emm.usp.br:8080/ramgen/eca/beaba_p3_modem.rm>.

Links para Real One Player para banda larga:

$<$ http://real.emm.usp.br:8080/ramgen/eca/beaba_p1_lan.rm>.

<http://real.emm.usp.br:8080/ramgen/eca/beaba_p2_lan.rm>. 
<http://real.emm.usp.br:8080/ramgen/eca/beaba_p3_lan.rm>.

Links para Windows Media Player - codec wm9:

$<$ mms://wms.emm.usp.br/eca/beaba_pl.wmv>.

$<$ mms://wms.emm.usp.br/eca/beaba_p2.wmv>.

$<$ mms://wms.emm.usp.br/eca/beaba_p3.wmv>.

Ou em <http://www.emm.usp.br $>$. Ir em "Galerias" $\rightarrow$ "Trabalhos realizados para ECA" $\rightarrow$ "beaba".

Resumo: O texto relata experiência em alfabetização audiovisual através da realização de oficinas de vídeo com adolescentes e professores de escolas municipais da Zona Leste de São Paulo. Os participantes passam por todas as funções básicas da produção em vídeo - roteiro, produção, câmera, entrevista, interpretação. Ao fazer narrativas audiovisuais, eles compreendem os elementos fundamentais da linguagem audiovisual e expressam seu próprio universo cultural. A oficina alfabetiza ao desmistificar equipamentos e estimular seu uso, revelando os recursos da linguagem audiovisual e resgatando o repertório passivo dos participantes. Produzir discursos com qualidade é a chave de uma dinâmica pedagógica transformadora. Os vídeos produzidos mostram um universo escolar muito diferente das representações das emissoras de televisão, contrapondo imagens da escola pública aos estereótipos da TV.

Palavras-chave: produção de vídeo, alfabetização audiovisual, cultura midiática, narrativas audiovisuais na escola pública.
Abstract: This article relates an experience in audiovisual literacy by the realization of video workshops with teenagers and teachers of some municipal public schools of the city of São Paulo. Participants go through all the basic steps of a video production - script, production, camera, interview, and interpretation. During audiovisual narratives, they understand fundamental elements of audiovisual language and express their own cultural universe. Literacy happens when the workshops demistify equipment and stimulate its use, revealing the resources of audiovisual language and redeems the participants' passive repertory. To produce speeches with quality is the key for a transforming pedagogical dynamic. The produced videos show a very different school universe from the representations of broadcasting corporations, opposing images of the public school to television stereotypes.

Keywords: video production, audiovisual literacy, mediatic culture, audiovisual narratives in public schools. 